\title{
Dos navios negreiros às balas perdidas: memória e decolonialidade na poética de Conceição Evaristo
}

\author{
De los barcos negreros a las balas perdidas: memoria y decolonialidad in \\ la poética de Conceição Evaristo
}

\author{
From slave ships to stray bullets: memory and decolonialiy in Conceição \\ Evaristo's poetry
}

\author{
Ernani Silverio Hermes ${ }^{1}$
}

\begin{abstract}
Resumo
A Literatura Brasileira contemporânea constitui-se como um campo discursivo plural e heterogêneo do qual emergem vozes subalternizadas historicamente pelo poder colonial. Nesse cenário, destaca-se a obra de Conceição Evaristo que, em seu fazer literário, vocaliza as vivências da mulher negra periférica projetada como "escrevivência", isto é, a articulação da experiência vivida pela escritora, e pelos que compartilham da identidade da mulher negra, na escrita literária. Ao partir desse contexto, tomo como objeto de estudo alguns poemas de Conceição, "Recordar é preciso", "Vozes-mulheres" e "Certidão de óbito", reunidos no livro Poemas de recordação e outros movimentos (2017). Para a análise, objetivo investigar as figurações da memória operadas pelo eu-lírico no resgate da matéria vivida e entender esse processo à luz da decolonialidade. Desse modo, procuro base teórica sobre memória em Paul Ricoeur, Michel Pollak e Maurice Halbwachs; ainda, para tratar da decolonialidade, recorro a Walter Mignolo, Aníbal Quijano, Eduardo Restrepo, Axel Rojas e Edward Said.
\end{abstract}

Palavras-Chave: Memória; Decolonialidade; Literatura Brasileira contemporânea; Conceição Evaristo.

\section{Resumen}

La Literatura Brasileña contemporánea se constituye como un campo discursivo plural y heterogéneo del cual emergen voces históricamente subordinadas por el poder colonial. En este escenario, destaca la obra de Conceição Evaristo, que, en su obra literaria, vocaliza las experiencias de la mujer negra periférica proyectada como "escrevivência", es decir, la articulación de la experiencia vivida por la escritora, y por los que compartem de la identidad de mujer negra, en la escritura literaria. A partir de este contexto, tomo como tema de estudio algunos poemas de Conceição, "Recordar é preciso", "Vozes-mulheres" y "Atestado de óbito", reunidos en el libro Poemas de recordação e outros movimentos (2017). Para el análisis, mi objetivo es investigar las figuraciones de la memoria operada por el yo lírico en el rescate de la materia vivida y entender este proceso a la luz de la decolonialidad. De esta manera, busco una base teórica sobre la memoria en Paul Ricoeur, Michel Pollak y Maurice Halbwacs; aun así, para lidiar con la decolonialidad, me dirijo a Walter Mignolo, Aníbal Quijano, Eduardo Restrepo, Axel Rojas y Edward Said.

Palabras- clave: Memoria; Decolonialidad; Literatura Brasileña contemporánea; Conceição Evaristo.

\begin{abstract}
Brazilian Contemporary Literature is built as a plural and heterogeneous discursive field from which emerge voices historically subalternized by the colonial power. Given this context, Conceição Evaristo's work stands out, she, in her literary creation, vocalize the experiences of black peripheral woman projected as escrevivência, that is, the conjoin of the experience lived by the writer, and those who share the black woman identity, in the literary writing. From this context, I chose as study object some poems by Conceição, "Recordar é preciso", "Vozes-mulheres", and "Certidão de óbito", joint in the book Poemas de recordação e outrosmovimentos (2017). To the analysis, I aim at investigating the memory figuration made by the lyric-self in the rescuing of the
\end{abstract}

${ }^{1}$ Licenciado em Letras; Universidade Regional Integrada do Alto Uruguai e das Missões; Frederico Westphalen, Rio Grande do Sul, Brasil; ernani.hermes@gmail.com 
of the lived experience and understand this process in the light of the decoloniality. Therefore, I search for a theoretical framework about memory in Paul Ricoeur, Michel Pollak and Maurice Halbwachs; also, to talk about decoloniality, I appeal to Walter Mignolo, Aníbal Quijano, Eduardo Restrepo, Axel Rojas, and Edward Said.

Keywords: Memory; Decoloniality; Brazilian Contemporary Literature; Conceição Evaristo.

"A nossa escrevivência não pode ser lida como histórias para ninar os da casa-grande e sim para incomodá-los em seus sonos injustos." Conceição

\section{Introdução} Evaristo

A Literatura Brasileira contemporânea é caracterizada pelas vozes históricas e sociais que emergem da sua poética. Esse resgate de discursos converge o olhar para questões históricas ainda abertas e que têm ressonância na atualidade. Nesse rol situa-se a ferida aberta da escravidão no Brasil, sustentada pelas estruturas de poder que ainda operam pela retórica da colonialidade, que molda o cenário contemporâneo marcado pelo racismo o genocídio da comunidade negra e a manutenção das dinâmicas sociais de subalternização.

Ilse M. R. Vivian (2019) assinala que essas novas perspectivas que se revelam na literatura atual dialogam com o projeto político-epistemológico da decolonialidade. Nesse processo, o fazer literário é articulado à memória e às construções de identidade, em uma investida de desconstruir as imagens do passado e do ser erigidas pelo discurso colonial. Desse modo, trazendo ao centro da criação literária essas vozes subalternizadas pelos processos históricos que, dessa forma, problematizam as formas de representação do passado e do sujeito.

É por esse viés que a práxis literária de Conceição Evaristo é estruturada. Ao colocar no centro da sua poética a voz da mulher negra subalternizada, propõe um diálogo entre as agruras do presente com as cicatrizes do passado. Sua obra transita por gêneros distintos: ensaio, poema, conto e romance. Neste último, destaca-se por Ponciá Vicêncio (2003) e Becos da memória (2006). Os livros Insubmissas lágrimas de mulheres (2001), Olhos d'água (2014) e Histórias de leves enganos e parecenças (2016) reúnem os contos da autora, além de participações em antologias, como os Cadernos Negros. Seus poemas encontram-se no livro Poemas de recordação e outros movimentos, publicado em 2017. Ademais, possui ensaios teóricos sobre literatura afro-brasileira e questões étnico-raciais publicados em diversas coletâneas.

Concentro-me, então, na análise de alguns poemas da autora, do livro Poemas de recordação e outros movimentos (2017), "Recordar é preciso", "Vozes-mulheres" e "Certidão de óbito". Pelos objetos escolhidos, objetivo discutir as figurações da memória efetuadas pelo 
eu-lírico dos poemas em interlocução com a decolonialidade, no sentido de reconstruir as representações do passado pela perspectiva dos sujeitos subalternizados historicamente.

Como sustentação teórica, defino memória a partir de Paul Ricoeur, Michel Pollak e Maurice Halbwachs. Ainda, discuto decolonialidade com base nos pressupostos de Walter Mignolo, Eduardo Restrepo, Axel Rojas, Aníbal Quijano e Edward Said.

\subsection{Estudos decoloniais e memória}

No contexto da segunda metade do século XX, simultâneo aos movimentos de independência das colônias, quando finda a era dos grandes impérios, surgem perspectivas críticas para (re)pensar as dinâmicas sociais, históricas, culturais e artísticas dos países que, ao longo dos séculos precedentes, experimentaram a subjugação pelo poder colonial europeu. Nesse cenário, emerge a teoria pós-colonial que redimensiona a cultura em relação às estruturas de poder erigidas pela lógica colonialista, bem como a constituição cruzada do sujeito colonizado e do sujeito colonizador. Concomitante, surgem os estudos subalternos, inicialmente, como uma forma de revisão da história indiana reconsiderando as posições entre as elites e as classes subalternizadas. No Japão, de forma congênere, surge a crítica desocidentalizante como uma alternativa de leitura ao paradigma ocidental, sobretudo, europeu. E, em meio a esses movimentos de resposta ao colonialismo, surgem os estudos decoloniais, de modo especial na América Latina e Caribe, que visam à problematização das epistemologias com base na hegemonia eurocêntrica.

Um dos marcos teóricos que fundamentam essas novas perspectivas epistemológicas é o livro Os condenados da terra, de Frantz Fanon, de 1963. Nesse texto basilar, fundamenta-se a visão dos condenados, ou seja, dos sujeitos colonizados. Tomando esse lugar de enunciação, o autor fala sobre a libertação dos povos que viverem sobre a violência histórica do colonialismo. A descolonização na ótica de Fanon é, então, um processo histórico que inclui a desordem e a violência. Nesse movimento está a criação de um novo homem, não mais a 'coisa' colonizada, mas um homem liberto.

Tanto é que, em Introducción critica al pensamiento decolonial (2009, p. 05), Eduardo Restrepo e Axel Rojas definem o pensamento decolonial como um bojo epistemológico que reflete sobre o lado sombrio da modernidade e é produzido pelos 'condenados da terra'. As problematizações feitas nesse âmbito teórico questionam a construção da lógica do sistemamundo moderno/colonial que erige o eurocentrismo e, com efeito, a colonialidade do ser, do 
saber e do poder. Tal operativo compreende, nesse viés, a desconstrução das hierarquias formuladas pelas estruturas coloniais de poder.

Walter Mignolo (2019), um dos precursores dos estudos decoloniais, em entrevista concedida a Luciano Gallas, entende que a colonialidade e a modernidade aproximam-se tendo em vista que esta não é um período histórico, mas uma autonarrativa europeia que a coloca como centro do mundo. A partir desse dimensionamento da Europa como centralidade, estabelecem-se as hierarquizações epistemológicas, alocando os saberes eurocêntricos em uma posição de centro, enquanto as epistemes e cosmovisões dos países colonizados são postas à margem.

Por essa estruturação emerge a "colonialidade do poder" que, segundo Mignolo (2010), é desdobrada no controle da economia, da autoridade, da natureza e seus recursos, do gênero e sexualidade, do conhecimento e das subjetividades. Desse modo, a colonialidade se manifesta por uma tripla dimensão: o poder, o saber e o ser. Tal tríade faz com que a decolonialidade, a partir da opção decolonial, questionem e problematizem as matrizes coloniais que fundamentam o pensar, o agir e o sentir.

Dessa perspectiva, fundamenta-se a homogeneização da compreensão de ser, centralizada no homem, branco, burguês, heterossexual. Assim, as questões de raça, gênero e classe são imbricadas pela dinâmica do poder colonial hegemonizante. De acordo com Aníbal Quijano (2000),

La colonialidad es uno de los elementos constitutivos y específicos del patrón mundial de poder capitalista. Se funda en la imposición de una clasificación racial/étnica de la población del mundo como piedra angular de dicho patrón de poder y opera en cada uno de los planos, ámbitos y dimensiones, materiales y subjetivas, de la existencia social cotidiana y a escala societal (QUIJANO, 2000, p. $342)^{2}$.

Pelos termos do teórico peruano, a colonialidade e o capitalismo compartilham dessa matriz de poder, sendo dois elementos que se retroalimentam. Essa padronização construída pelas dinâmicas de poder são colocadas em vistas de dominação, uma vez que ao homogeneizar as identidades, acentua-se a dominação dos corpos. De uma forma bastante aguda, as categorias da raça/etnia são centrais nessa dinâmica de dominação, sendo o âmago desse sistema que se constitui como um padrão global de poder.

Por esse contexto, entendo a decolonialidade a partir de Mignolo (2008), sendo que esse conceito

\footnotetext{
2 A colonialidade é um dos elementos constitutivos e específicos do padrão mundial de poder capitalista. Se funda na imposição de uma classificação racial/étnica da população do mundo como pedra angular do dito padrão de poder e opera em cada um dos planos, âmbitos e dimensões materiais e subjetivas, da existência social cotidiana e da escala social (tradução minha).
} 
significa ao mesmo tempo: a) desvelar a lógica da colonialidade e da reprodução da matriz colonial do poder (que, é claro, significa uma economia capitalista); e b) desconectar-se dos efeitos totalitários das subjetividades e categorias de pensamento ocidentais (por exemplo, o bem sucedido e progressivo sujeito e prisioneiro cego do consumismo) (MIGNOLO, 2008, p. 313).

Isto é, a postura decolonial implica em desvelar e desconstruir a retórica colonial que que tem como efeito primeiro a instituição de hierarquias e, por extensão, a dominação do outro. E, a partir dessa perspectiva, redimensionar as compreensões acerca do ser, do poder e do saber. Assim, conectando os dois elementos apontados pelo autor, em que as epistemologias impregnadas pela colonialidade direcionam a processos de subjetivação de dominação manifestados, no mundo contemporâneo, pelos padrões de consumo impostos pelo capitalismo.

A retórica colonial e imperialista a que me refiro é explicada por Edward Said, em Cultura e Imperialismo (2011), cujo entendimento aponta que

\begin{abstract}
Nem o imperialismo, nem o colonialismo é um simples ato de acumulação e aquisição. Ambos são sustentados e talvez impelidos por potentes formações ideológicas que incluem a noção de que certos territórios e povos precisam e imploram pela dominação, bem como formas de conhecimento filiadas à dominação: o vocabulário da cultura imperial oitocentista clássica está repleto de palavras e conceitos como "raças" servis" ou "inferiores", "povos subordinados", "dependência", "expansão" e "autoridade" (SAID, 2011, p. 43, grifos do autor).
\end{abstract}

Assim, as estruturas de poder coloniais fundamentam-se na ideia autocentrada de superioridade de um povo em detrimento do outro, este que precisa ser dominado; o que se observa pela forma como a Europa - e também os Estados Unidos - se projetam em relação aos demais. É essa retórica que fundamenta a ideia colonial de que a colonização foi a salvação dos povos. Esse posicionamento manifesta-se tanto no colonialismo clássico, das expansões além-mar, quanto nas formas contemporâneas de colonização, que compreendem à dominação econômica, política e cultural dos chamados países de primeiro mudo em relação aos do terceiro. São justamente esses discursos e sistemas de representação que a crítica decolonial visa desconstruir.

Sendo, portanto, a decolonialidade uma perspectiva de reconstrução do capital simbólico que fundamenta a construção das identidades e dos discursos, faz-se necessário que a memória, que baliza tais produções, seja também redimensionada. Nesse sentido, entendo a memória a partir de Paul Ricoeur que, em A memória, a história, o esquecimento, aponta que "não temos nada melhor que a memória para significar que algo aconteceu, ocorreu, se passou antes que declarássemos nos lembrar dela" (RICOEUR, 2007, p. 40). Assim, a memória é posta como um meio de significação do passado, que é trazido à tona no momento da rememoração. Ademais, tal procedimento de recuperação do passado é efetivado por meio de 
imagens: "Dizemos indistintamente que nós representamos um acontecimento passado, ou que temos uma imagem, que pode ser quase visual ou auditiva" (RICOEUR, 2007, p. 25, grifos do autor). Logo, a rememoração é a ressignificação do passado por meio de imagens projetadas à consciência, em um constante processo de reelaboração da matéria pretérita.

Nas discussões sobre memória, os postulados de Maurice Halbwachs (2003) vêm à tona a partir da ideia de memória coletiva. Sobre isso, o sociólogo francês diz que "a memória individual é um ponto de vista sobre a memória coletiva" (HALBWACHS, 2003, p. 69). Isto quer dizer que no ato da rememoração não existe apenas a perspectiva individual, mas também se alicerçam nos testemunhos e perspectivas de outros sujeitos que compõem a comunidade. Nesse sentido, ao pensar na representação do passado o operativo efetuado não é unicamente individual, mas coletivo, pois nessa atividade representativa fazem-se presentes narrativas, discursos e imagens que não são exclusivos do indivíduo, mas que vêm de uma coletividade.

Assim, há um enquadramento da memória, operação esta definida por Michael Pollak (1989, p. 9) como "tentativas mais ou menos conscientes de definir e de reforçar sentimentos de pertencimento e fronteiras sociais entre coletividades". Assim, a construção de um capital mnemônico de um grupo social é realizado por uma série de estratégias que fazem uma espécie de curadoria do que irá, ou não, compor esse quadro memorial. Desse modo, a identidade desse coletivo é, visivelmente, afetada por essa construção de memória, pois os sentidos que constroem sobre o seu passado é decisivo para o seu agenciamento e para as negociações identitárias que efetuam.

Por essa perspectiva é que a memória e a decolonialidade se imbricam, visto que as representações do passado, construídas na forma de imagens projetadas pelo imaginário, precisam ser operadas a partir de uma postura decolonial. Isto é, propor uma abertura aos sistemas representacionais que significam a experiência pretérita considerando a perspectiva dos 'condenados da terra'. Essa perspectiva, no entanto, não é individual, mas, sim, uma perspectiva coletiva, em que a memória do sujeito é constituída pela ancestralidade e pelas vivencias da comunidade em que está inserido.

Tal investida sobre a memória é necessária pelo fato de que o discurso memorialístico e histórico é erigido, nas sociedades colonizadas, pela perspectiva única do colonizador. Essa revisão do passado é, essencialmente, uma postura descolonializante, tendo em vista que ao voltar à experiência do colonizado reavaliam-se as cosmologias, saberes e vivências que orientam a compreensão sobre o pensamento, a agência e a subjetividade. 
A literatura, nesse sentido, desempenha um papel de relevância, pois torna-se um espaço de resgate das vozes e experiências que sofreram tentativas de apagamento no decorrer da história. Desse modo, apresenta alternativas às compreensões de mundo e de ser atravessadas pela investida colonialista de homogeneização.

\subsection{As vozes da poética de Conceição Evaristo}

Maria da Conceição Evaristo de Brito, nascida no estado de Minas Gerais em 1946, traça um itinerário desde sua juventude como empregada doméstica até o seu reconhecimento como escritora. Graduou-se em Letras, pela Universidade Federal do Rio de Janeiro, trabalhou como professora da rede pública e galgou títulos acadêmicos, mestrado e doutorado, na área de Literatura. Conceição destaca-se como uma das grandes ficcionistas e, também, como intelectual que propõe interpretações sobre as agruras do Brasil contemporâneo e do seu passado lacunar por meio da sua crítica e da sua escrita literária. Esse operativo é feito ao recuperar a experiência da escravatura para trabalhar com a marginalização da comunidade negra nos dias de hoje.

Conceição (2005) define o seu empreendimento de escrita como "escrevivência", compreendendo que

Surge a fala de um corpo que não é apenas descrito, mas antes de tudo vivido. A escre(vivência) das mulheres negras explicita as aventuras e as desventuras de quem conhece uma dupla condição, que a sociedade teima em querer inferiorizada, mulher e negra. [...] Pode-se dizer que os textos femininos negros, para além de um sentido estético, buscam semantizar um outro movimento, aquele que abriga toda as suas lutas. Toma-se o lugar da escrita, como direito, assim como se toma o lugar da vida (EVARISTO, 2005, p. 205-206, grifos da autora).

O termo composto pela justaposição de "escrita" e "vivência" significa essa projeção da experiência vivida pela mulher negra na escritura. Assim, trazendo a ideia de escrever a vivência dessa identidade subalternizada pelas estruturas de poder colonial por meio da escrita, espaço historicamente pertencente às elites. Desse modo, ao significar as experiências da mulher negra na escrita o silenciamento é rompido e, assim, ao ter lugar no campo escritural, toma também o seu espaço no mundo.

Dito isso, concentro-me na análise de alguns poemas de Conceição Evaristo focalizando nas vozes que emergem de sua poética, sobretudo, nas evocadas pela memória e a perspectiva descolonializante que vocalizam. O primeiro poema ao qual me dedico é "Recordar é preciso" 3 que, desde o título, faz presente a figuração da memória.

\footnotetext{
${ }^{3}$ Os poemas aqui analisados integram ao livro Poemas de recordação e outros movimentos, contudo são capturados da seguinte referência: Confira os 10 melhores poemas de Conceição Evaristo. Disponível em:
} 


\author{
Recordar é preciso \\ O mar vagueia onduloso sob os meus pensamentos \\ A memória bravia lança o leme: \\ Recordar é preciso. \\ O movimento vaivém nas águas-lembranças \\ dos meus marejados olhos transborda-me a vida, \\ salgando-me o rosto e o gosto. \\ Sou eternamente náufraga, \\ mas os fundos oceanos não me amedrontam \\ e nem me imobilizam. \\ Uma paixão profunda é a bóia que me emerge. \\ Sei que o mistério subsiste além das águas. (EVARISTO, 2019, s/p).
}

Desde o título do poema a memória é figurada ao indicar a necessidade de lembrar. Os três primeiros versos, enunciados pela voz feminina do eu-lírico, recorrem a uma imagística do mar: caminho cruel pelo qual os antepassados negros foram trazidos da África como traficados para trabalhar nas Américas. Assim, evocando uma memória atrelada à ancestralidade negra, da sua diáspora e da sua exploração. A memória, então, lança o leme, peça pela qual o navio é guiado, ou seja, é a memória que conduz de volta o eu-lírico ao passado e impera a necessidade desse retroceder, a necessidade da rememoração.

Os três versos que seguem valem-se de metáforas poéticas em que as lembranças são como as águas do mar: vem e vão na forma de ondas, significando a dialética entre o lembrar e o esquecer. Contudo, tais lembranças são salgadas, como a água dos oceanos, e banham o rosto, assim, comparando com as lágrimas que evocam a dor das reminiscências por trataremse de imagens do sofrimento e da violência do tráfico de escravos.

Nos próximo trio de versos, o eu-lírico diz ser eternamente naufraga e, de acordo com o que precede, estar naufraga significa viver nos limites entre o lembrar e o esquecer, entre o passado ancestral da África para as lavouras de senhores brancos e o presente que marginaliza a sua identidade, sendo que as imagens que irrompem desse movimento não a assustam mais. Desse modo, lembrar o passado de violência é lutar contra o poder que o sustentava e, diante das constantes lutas, ele não pode mais amedrontar.

Nos dois últimos versos, que finalizam o poema, o eu-lírico reconhece que nisso tudo há um mistério, uma vez que nem tudo foi elucidado sobre a história da escravidão. Todavia, há algo nesse amálgama de histórias, nesse mar de lembranças, é esse o ponto de partida para o seu exercício de rememoração e, consequentemente, de ressignificação do passado.

No próximo poema, Conceição continua a desenvolver esse resgate de vozes de sua ancestralidade ressignificadas pela rememoração, no poema "Vozes-mulheres":

<http://notaterapia.com.br/2019/11/05/confira-os-10-melhores-poemas-de-conceicao-evaristo/>. 2019. Acesso em $22 / 07 / 2020$. 


\author{
Vozes-mulheres \\ A voz de minha bisavó \\ ecoou criança \\ nos porões do navio. \\ ecoou lamentos \\ de uma infância perdida. \\ A voz de minha avó \\ ecoou obediência \\ aos brancos-donos de tudo. \\ A voz de minha mãe \\ ecoou baixinho revolta \\ no fundo das cozinhas alheias \\ debaixo das trouxas \\ roupagens sujas dos brancos \\ pelo caminho empoeirado \\ rumo à favela. [...] (EVARISTO, 2019, s/p).
}

O eu-lírico traz à tona as vozes da bisavó atreladas aos porões dos navios negreiros, que fazia o transporte dos escravos; da avó em relação aos senhores brancos; da sua mãe nas cozinhas dos patrões rumo à favela. Aqui relaciona-se à memória as vozes aos espaços ocupados pelos sujeitos que elas remetem: o navio negreiro, as fazendas, a favela. Assim, delineando o rumo do negro na história iniciado com o tráfico da África dessa população desterritorializada, arrancada da sua cultura e do seu lugar, para ser explorado em outro; em seguida, a vida do escravo nascido no Brasil, que já nascia pertencente a um senhor, como uma mercadoria, como um objeto, que tiveram seus corpos mercantilizados e violados; e, por último, a sina dos descendentes de escravos alocados nas favelas.

Em seguida, o eu-lírico situa a sua própria voz e a voz da sua filha:

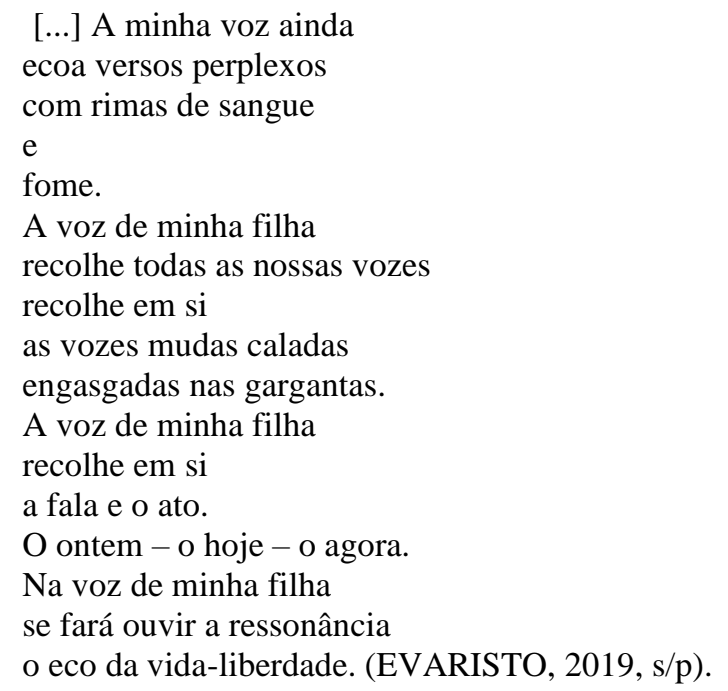

Assim, o eu-lírico que representa o presente, como a união de todas essas vozes do passado, essas vozes silenciadas pela história que ecoam por meio da memória vocalizada por essa voz do presente. Desse modo, delineia-se a memória coletiva, cuja constituição é atravessada por essa multiplicidade de vozes: a voz da bisavó, da avó e da mãe. Em versos 
metalinguísticos, "ecoa versos perplexos / com rimas de sangue / e / fome", o eu-lírico situa de que perspectiva enuncia esses versos, que é a dos sobreviventes do massacre colonial, que tem a sua experiência significada por sangue e fome que remetem à violência e às desigualdades sociais da comunidade negra. E, em meio a isso, projeta na voz da filha, que enunciará no futuro, a esperança da liberdade, em que os seus estarão livres das opressões de raça e gênero. É nesse futuro de libertação que está a criação do novo sujeito, que, nas pontuações de Fanon (2004), é um dos operativos centrais da descolonização.

Pelos versos do poema, transpassam-se diferentes temporalidades trazidas pelas vozes resgatadas: o passado na voz das antepassadas, o presente na sua voz e o futuro na voz da filha. Desse modo, construindo os sentidos do poema pela memória e pela ancestralidade em que a relação ancestral das "vozes-mulheres" que enunciam conectam as diferentes perspectivas da História. Essas pontas distintas, do passado de escravidão, são amarradas às vivências de hoje, nas favelas, construindo a imagem da constante subalternização da comunidade negra.

O terceiro poema que trago é "Certidão de óbito":

\section{Certidão de óbito}

Os ossos de nossos antepassados

colhem as nossas perenes lágrimas pelos mortos de hoje.

Os olhos de nossos antepassados, negras estrelas tingidas de sangue, elevam-se das profundezas do tempo cuidando de nossa dolorida memória.

A terra está coberta de valas

e a qualquer descuido da vida

a morte é certa.

A bala não erra o alvo, no escuro

um corpo negro bambeia e dança.

A certidão de óbito, os antigos sabem,

veio lavrada desde os negreiros. (EVARISTO, 2019, s/p).

O título do poema deixa claro do que se trata: a morte, mais especificamente, o genocídio negro da escravidão colonial até nossos dias. O eu-lírico ressignifica o massacre orquestrado pelos senhores durante a escravatura e pelos comerciantes de escravos na captura e translado e os conecta ao genocídio negro na atualidade na forma das "balas perdidas", como é colocado pela versão oficial do Estado.

Pelo operativo poético rompe-se a linha da história da escravatura com a história contemporânea evidenciando como o corpo negro é concebido pelas estruturas de poder construídas pela ideologia colonial: algo a ser explorado e destruído. Isso que é colocado de forma explícita no poema pelos "ossos de nossos antepassados / colhem as nossas perenes lágrimas / pelos mortos de hoje". Aqui, novamente a "dolorida memória" da ancestralidade é 
evocada para lançar luz ao presente, em que, entre as mortes do assado e as de hoje, há uma linha que as une e dimensiona o itinerário da comunidade negra às sombras da violência histórica do colonialismo, desde o tráfico negreiro até a destruição dos corpos negros na atualidade. Nesse sentido, a imagem poética da morte é construída no poema pelos signos evocados: os ossos, as valas, as balas. Essa imagística desvela a violência estrutural que foi construída a partir da mecânica colonialista de organização social, em que o racismo está na espinha dorsal da estrutura de sustentação das sociedades colonizadas.

Os três poemas de Conceição, compostos em versos livres, afastados da métrica tradicional, dão forma a essa vivência da mulher negra permeada pelos signos da violência, desde os seus antepassados até os seus de agora, mortos pelas engrenagens de um sistema estruturalmente racista e colonial. Ao descortinar esse cenário, emerge uma perspectiva de resistência ao poder e aos discursos oficialmente instituídos, que negligenciam e, além disso, mantém esse cenário de massacre da população negra.

O jogo operado pela poética de Conceição, nesse sentido, é atravessado pelo tempo na forma da história e da memória. Da história porque resgata a violência histórica da escravidão e do tráfico de escravos sustentados pelo poder colonial. E, da memória, porque evoca a sua ancestralidade que influencia na subjetivação, ou seja, na forma como o eu-lírico se vê como sujeito e as relações que estabelece com os seus antepassados.

O crítico mexicano Octavio Paz (2012), em $O$ arco e a lira, defende que há uma relação inegável entre os signos da poesia e a história, uma vez que o poético é inseparável das manifestações históricas e sociais. Ainda, é histórico porque pertence a um povo e ao seu momento de fala e, ainda, o poema e a comunidade se alimentam mutuamente, pois "sem palavra poética tampouco há sociedade" (2012, p. 192).

Desse modo, a poesia opera em uma via de mão dupla: ao passo que reinterpreta o passado a partir do olhar contemporâneo, lança novos sentidos às dinâmicas sociais da atualidade ao conectá-las ao pretérito. Como afirma Edward Said, "a invocação do passado constitui uma das categorias mais comuns nas interpretações do presente" (2011, p. 34).

Por essa perspectiva, a poética de Conceição Evaristo sustenta-se pela memória e pelo resgate das vozes da sua ancestralidade. Essa operação efetuada pela escrevivência é uma expressão de decolonialidade, pois desconstrói as epistemologias da história acerca do passado construídas pelas estruturas coloniais de poder e enuncia um discurso que ressignifica o pensar, o agir e o ser pelo viés das vítimas do massacre colonial.

Said entende que "a descolonização é uma complexíssima batalha sobre o rumo de diferentes destinos políticos, diferentes histórias e geografias, e está repleta de obras de imaginação, erudição e 
contraerudição" (2011, p. 343). Assim erige-se a poética da autora, redimensionando o capital simbólico que fundamenta o imaginário e as narrativas dos processos de formação social, histórica, política e cultural do país colonizado.

\section{Considerações finais}

Sem dúvidas, a perspectiva decolonial é uma das tendências que mais se destacam no cenário da crítica contemporânea. Esse viés faz-se necessário para que haja um redimensionamento das epistemologias e cosmologias impostas aos países colonizados pelas investidas coloniais e imperialistas. Trazendo, nesse sentido, um diálogo profícuo entre a arte, a cultura, o conhecimento e a política, que impulsiona novas compreensões sobre o pensamento, a ação e as formas de nos constituirmos como sujeitos.

Na Literatura Brasileira contemporânea a voz de Conceição Evaristo projeta novos sentidos para a história e para as dinâmicas sociais da atualidade ao enunciar um discurso pautado pela experiência da mulher negra. Pelos poemas analisados, observo que as figurações da memória e o resgate de vozes historicamente silenciadas situam-se no centro da sua poética e, desse modo, faz emergir uma perspectiva decolonial no âmago da produção literária atual.

Dessa forma é que intitulo este artigo, "Dos navios negreiros às balas perdidas". Essas duas imagens de violência amarram as duas pontas da História, o passado e o presente: os navios, chamados também de tumbeiros, pois eram a tumba de muitos homens negros e de muitas mulheres negras que não conseguiam sobreviver à desumanidade do tráfico, representam a violência ancestral, de arrancar uma comunidade da sua terra e ser explorada em uma terra estranha sob condições desumanas; as balas remetem ao genocídio da comunidade negra de hoje, que nas favelas, nas periferias, são massacrados por conta de uma estrutura social racializada, herança colonial, em que, para utilizar os termos a canção "A carne", composta por Marcelo Yuka, Seu Jorge e Ulisses Cappelletti, "a carne mais barata do mercado é a carne negra". Esses dois cenários de violência são interligados pela poética de Conceição Evaristo, que recupera uma memória ancestral em benefício de uma ressignificação do passado e uma interpretação do presente. Tal movimento dialoga com o projeto político-epistemológico da decolonialidade, pois desconstrói um capital simbólico de memória construído pela colonialidade e o reconstrói na perspectiva dos 'condenados da terra'.

\section{Referências}

Confira os 10 melhores poemas de Conceição Evaristo. Disponível em: $<$ http://notaterapia.com.br/2019/11/05/confira-os-10-melhores-poemas-de-conceicaoevaristo/>. 2019. Acesso em 22/07/2020.

EVARISTO, Conceição. Gênero e etnia: uma escre(vivência) de dupla face. In: MOREIRA, Nadilza Martins de Barros; SCHNEIDER, Liane (Orgs.). Mulheres no mundo: etnia, marginalidade e diáspora. João Pessoa: Ideia, 2005. p. 201-212. 
EVARISTO, Conceição. Poemas da recordação e outros movimentos. Nandyala, 2008.

FANON, Frantz. The wretched of the Earth. Trad. Richard Philcox. New York: Grove Press, 2004.

HALBWACHS, Maurice. A memória coletiva. Trad. Beatriz Sidou. São Paulo: Centauro, 2003.

MIGNOLO, Walter D. Desobediência epistêmica: a opção descolonial e o significado de identidade em política. Cadernos de Letras da UFF: Dossiê: Literatura, língua e identidade, n.34, p.287-324, 2008. Disponível em: 〈www.uff.br/cadernosdeletrasuff/34/traducao.pdf>. Acesso em: 26/07/2020.

MIGNOLO, Walter. Decolonialidade como o caminho para a cooperação. [Entrevista concedida a Luciano Gallas]. Trad. André Langer. Revista do Instituto Humanitas Unisinos, São Leopoldo, ed. 431, 2019. Disponível em: < http://www.ihuonline.unisinos.br/artigo/5253walter-mignolo>. Acesso em 26/07/2020.

MIGNOLO, Walter. Desobediencia epistémica: retórica de la modernidad, lógica de la colonialidad y gramática de la descolonialidad. Argentina: Ediciones del signo, 2010.

PAZ, Octavio. O arco e a lira. Trad. Ari Roitman e Paulina Wachr. São Paulo: Cosac Naify, 2012.

POLLAK, Michael. Memória, esquecimento e silêncio. Estudos Históricos, Rio de

Janeiro, vol. 2, n. 3, 1989, p. 3-15. Disponível em: http://bibliotecadigital.fgv.br/ojs/index.php/reh/article/view/2278/1417. Acesso em $26 \mathrm{dez}$ de 2020.

QUIJANO, Aníbal (2000). "Colonialidad del poder y clasificación social". Journal of worldsystems research, v. 11, n. 2, p. 342-386. Disponível em: < http://www.ramwan.net/restrepo/poscolonial/9.2.colonialidad\%20de1\%20poder $\% 20 \mathrm{y} \% 20$ clasificacion $\% 20$ so cial-quijano.pdf>. Acesso em: 26/07/2020.

RESTREPO, Eduardo; ROJAS, Axel. Introducción critica al pensamiento descolonial. Maestría en Estudios Culturares. Bogotá: Universidad Javeriana, 2009.

RICOEUR, Paul. A memória, a história, o esquecimento. Trad. Alain Françoi [et al.]. Campinas: Editora da Unicamp, 2007.

SAID, Edward. Cultura e imperialismo. Trad. Denise Bottmann. São Paulo: Companhia das Letras, 2011.

YUKA, Marcelo; JORGE, Seu; CAPPELlETTI. A carne. Disponível em: <https://www.letras.mus.br/seu-jorge/a-carne/Acesso em: 27/12/2020.

VIVIAN, Ilse MR. O inventário das coisas ausentes: memória, diáspora e descolonização na literatura brasileira contemporânea. ANTARES: Letras e Humanidades, v. 11, n. 22, p. 58-71, 2019. 